\title{
Avoiding extinction: the future of economics
}

\author{
Graciela Chichilnisky
}

Columbia University, New York 10027, USA

E-mail: chichilnisky1@gmail.com

\begin{abstract}
New physical constraints emerged in the 20th century and are changing the decision criteria used until now. Two optimisation problems are equivalent: (1) maximising discounted utility with a long-run survival constraint and (2) maximising a new type of utility that treats the present and future equally. The latter originates in normative axioms introduced by the author in Chichilnisky (1996a), which capture the essence of sustainable development. The article shows that in the economics of the future, normative and positive goals converge: the axioms representing what we would like merge with what will be observed. The 'weight' given to the long-run future is identified with the marginal utility of an environmental asset along a path that narrowly avoids extinction. No prior welfare criteria satisfy the axioms for sustainable development introduced by Chichilnisky (1996a; 1997). The implied decision criteria have practical implications for new forms of costbenefit analysis, choices under uncertainty, optimal extraction of renewable resources and the optimisation of investment and trade. These preferences have been tested experimentally (Chanel and Chichilnisky, 2008) and identify the limits of nonparametric econometrics (Chichilnisky, 2009c).
\end{abstract}

Keywords: sustainable development; axioms for sustainable development; dictatorship of the present and the future; extinction; equal treatment for the present and the future; long-run optimisation; intergenerational equity; efficiency; basic needs; green economics.

Reference to this paper should be made as follows: Chichilnisky, G. (2009) 'Avoiding extinction: the future of economics', Int. J. Green Economics, Vol. 3, No. 1, pp.1-18.

Biographical notes: Graciela Chichilnisky is a world renowned Economist and Mathematician and the creator of the carbon market of the Kyoto protocol that is international law since 2005. She also created the concept of Basic Needs and financial instruments known as 'catastrophe bundles' that are widely used in the reinsurance industry. A Chaired Professor at Columbia University in Economics and in Mathematical Statistics, she advises national governments and international organisations such as the United Nations, the IMF and the World Bank and has been the founder and CEO of two global financial companies in New York, London and Tokyo. A prolific author, she has taught at Harvard and Stanford Universities and held the Keynes Chair at the University of Essex in the UK and her most recent books are Saving Kyoto and Beyond the Global Divide: From Basic Needs to the Knowledge Revolution, to appear in 2009 and 2010.

Copyright @ 2009 Inderscience Enterprises Ltd. 


\section{Introduction}

Public opinion seems to be shifting, showing a growing interest in sustainable development that takes into account the needs of future generations. This shift comes at a time when we face potentially catastrophic risks that can threaten our civilisation, some of which were created by human impacts on planetary processes such as global warming and biodiversity destruction. ${ }^{1}$ In reality over $99.9 \%$ of all species that ever existed have gone extinct, ${ }^{2}$ and therefore extinction is the rule not the exception. Thus a concern for our long term future seems reasonable: it may come from an atavistic instinct for survival that would be natural to a species like ours that has been around, with its close relatives, for about four million years (Chichilnisky, 2009b; Chichilnisky and Sheeran, 2009). Sustainable development is a realistic response to concerns about survival (e.g., Hoerschele, 2008; Kennet and Heinemann, 2006; Kennet, 2006; 2008). ${ }^{3}$ Yet sustainable development is hardly a new issue. The need for development that satisfies the basic needs of present and future generations was introduced 30 years ago in Chichilnisky (1977a-b), Herrera et al. (1976) and Chichilnisky et al. (1998); it was developed in many country studies by the $\mathrm{ILO}^{4}$ and the World Bank and was recommended by international vote as a global development priority at the 1992 Earth Summit of Rio de Janeiro (see Brundtland, 1987). ${ }^{5}$ Yet the challenge to achieve sustainable development and satisfy basic needs remain today as elusive as ever.

The goals of sustainable development are more compelling today than ever. At the same time one observes a disconnect between mainstream economics and global environmental issues. Economics is heavily implicated in the environmental risks we face. Global warming arises from the use of fossil energy in industrial production, and biodiversity destruction and the depletion of clean water sources from the use of watersheds, forests and the oceans for production and trade. Economics, particularly market economics, is heavily implicated in all these matters. ${ }^{6}$ Global environmental issues highlight the short - term nature of economics, ${ }^{7}$ which seems increasingly unable to offer solutions to public concerns about our long run future. Caught in this widening disconnect is the future of economics as a science.

The economics of the future is being created today, and markets are part of the solution as much as part of the problem. The single global agreement that we have to avert climate change, the United Nations Kyoto Protocol, is driven by a new type of market, the carbon market, which trades global public goods that are privately produced: the rights to emit carbon and thus alter the quality of the planet's atmosphere. The carbon market, which was introduced and drafted by the author into the Kyoto Protocol in 1997, is a new type of market that joins together the imperatives of equity and efficiency because of its unusual characteristics: it trades a type of good that the world never saw before, partly a public good because carbon concentration is the same the world over and partly a private good because we produce carbon through our private economic activities.

Market economics will continue to be implicated in global environmental problems for the foreseeable future. Thus to make progress we need a reconsideration of economics, and particularly of the notion of economic value. This need seems generally recognised. For many years there have been efforts to create green measures of GDP, cf. Chichilnisky (1998a) to redress the notion of economic value. But these well meaning efforts put the cart before the horse. We know from Adam Smith's Invisible Hand that markets are driven by individual gain. Therefore a change in individual preferences 
seems essential. We cannot expect that change will happen solely from the top - by laws or decrees for new measures of GDP. We need a change in individual preferences, on how we value long run survival, that can drive a change in market values and redefine economic performance.

To a certain extent, a change in preferences is under way. The shift we observe in public opinion is a powerful measure of change. But we need to understand what is driving this change, and how to help orient it into a useful reconsideration of economic value and more generally of economics as a science. We need to understand how preferences change and how their change inserts into the everyday economic activities such as market trading, cost benefit analysis, investment, and more generally the operation of real and financial markets. This is the motivation for the article.

\section{A sea change in preferences}

Why is a change in values and preferences occurring today - why now? This article argues that the sea change we observe is due to objective and rational reasons that can be observed and quantified. Knowledge of these reasons can help us reconsider economic thinking and in the process create the economics of the future. The idea is simple: we are changing preferences because the situation itself has changed. External change is driving our economic values and causing a change in preferences.

The change I am talking about is the objective realisation that we may be facing extinction as a species sooner rather than later - moreover, that we could be causing our own extinction. Let me explain how this alters our preferences, why the mechanism of change is important, and how we can use it build step by step the economics of the future without throwing away the baby with the bath water.

Implementing sustainable development is a moving target that requires more than public attention and a change in values and preferences. It requires a solid analysis of sustainability with the level of clarity and substance of neoclassical theory, ${ }^{8}$ to support the practical scope and the current widespread use of markets, investment, and cost benefit ${ }^{9}$ analysis. The crux of the matter is how, through markets, we can redefine economic values that go beyond immediate individual and immediate gain and encompass the needs of future generations. This motivation led me to propose in 1993 two axioms that define sustainable development by requiring equal treatment for the present and for the future and to derive the decision criteria that they imply (Chichilnisky, 1996a; 1997). These were 'normative' axioms, they indicated a desirable way to proceed - not the way things are. This article deals directly with 'positive' economics - not the way we want things to be, but the way things are. What this article shows in Theorem 4 is that - somewhat surprisingly - once we become aware of new long term physical constraint on resources, such as the possible extinction of a species even in the long run, this invokes new behavioural axioms I introduced (Chichilnisky, 1996a), that require equal treatment of the present and the future and we behave according to the decision criterion they imply. This article shows that the 'equal treatment' axioms are equivalent to awareness of physical limits in the long run future. Therefore the new axioms are the essence of sustainable development, the economics of the future. 
Here and in parallel work we show how to operationally use these axioms on an everyday basis to create the markets of the future, to build the cost benefit tools of the future, to measure GDP in a way that is sensitive to the future, to make choices under uncertainty, and to create investment rules for the future of the global economy.

A major physical transition has taken place since the middle of the 20th century, a period in which most economic analysis of preferences was developed, e.g., Koopmans (1960) and Chichilnisky and Sheeran (2009). ${ }^{10}$ For the first time in history, humans dominate the planet and consume resources in a way that can alter the planets climate, its water bodies and its biological mix. Fossil fuel energy used for production since the Second World War emitted carbon that could alter irreversibly the earth's climate with catastrophic consequences. Biologists see the loss of biodiversity during the last 60 years as one of the four or five largest incidents of destruction of life on the planet, 1000 times larger ${ }^{11}$ than what is observed from fossil records. ${ }^{12}$ The voracious use of resources since World War II originated largely in the industrial countries, and was accompanied by increasing discrepancies in resource consumption between industrial and developing countries, the North and the South (see Chichilnisky, 2009b; Chichilnisky and Sheeran, 2009). The problem has been high in the international agenda since the 1992 United Nations Earth Summit in Rio de Janeiro, where the issue of sustainable development emerged as one of the most urgent topics of international policy and 150 nations endorsed UN Agenda 21 requiring new patterns of sustainable development that can satisfy the basic needs of the present and the future. ${ }^{13}$ Yet since 1992 the global use of resources and the difference of consumption between poor and rich nations has only increased, and the changes we are precipitating in the atmosphere, water and land threaten the future of humankind. This is the objective basis of change on which the new preferences are emerging.

Here is how the rest of the article is organised. First we explain the experimental evidence on how we value the long run. Then we summarise the 'equal treatment' axioms for the present and the future introduced in Chichilnisky (1996a), that attempt to explain the experimental evidence. These have not been debated, partly because there is general agreement that economics has to take account of the long run (see Cline, 1992; Cropper et al., 1994; Dutta, 1991; Hammond, 1993; Heal, 2000; Krautkramer, 1985; Lowenstein and Elster, 1992; Solow, 1992). Nevertheless three outstanding issues emerged in the ensuing literature ${ }^{14}$ and are explained here. The first is the origin of the new axioms - where do they come from? Why do the issues of sustainable cost benefit analysis, sustainable preferences and sustainable markets, arise today and not before? It seems important to know, because only a rapid change of preferences can help achieve sustainable development. Theorem 3 shows that if we are aware of long term constraints, then we must accept the two 'equal treatment' axioms proposed in 1993 and the decision criteria that they imply, since both criteria lead to the same decisions. The new axioms are equivalent to the awareness of physical limits in the long run future.

A second related issue is how to compute the 'weight' that is assigned to the long run future by the sustainable preference. The initial representation theorem for 'sustainable preferences' provided in Chichilnisky (1996a) had a degree of freedom for this parameter, which remained undefined. This can be considered a useful feature of the theory, and parallels the two degrees of freedom that appear in traditional discounted utility analysis introduced by Koopmans (1960), namely the 'instantaneous utility', and the 'discount factor' that are used to define discounted utility, both of which are left 
undefined. Yet it can be useful to identify the value of the 'weight' between the present and the future in special cases, to show how it can be computed in practice. In this article we consider a special case: the case of renewable resources that can become extinct when overused, a timely issue since $25 \%$ of all known mammals are now extinct (Schipper et al., 2008). Theorem 4 establishes that optimising according to the new axioms and the attendant preferences, is equivalent to optimising based on a new physical constraint on the resource in the long term. The 'weight' assigned to the future is the marginal utility of the resource at the point of extinction. This is the point where the resource is presumably most valuable.

The results provided here add a new angle to the initial axioms and the sustainable preferences they imply. They help to compute solutions and explain further the emergence of sustainable preferences as awareness about the depth and scope of biodiversity destruction and the risk of potentially catastrophic climate change in the long run future. In other words, to change our preferences what is needed is to increase awareness of the new long term physical constraints. The last section examines a list of previously used preferences and shows that none satisfy the axioms of sustainability defined here, so this theory of sustainable development represents genuine change.

\section{Experimental evidence on how we value the long run}

In the last 20 years many experiments have measured how people value the long run (see, e.g., Lowenstein and Thaler, 1989; Cropper et al., 1994; the references in Lowenstein and Elster, 1992). Their findings clash with the traditional discounted approach. People value the present and the future differently from the predictions of the standard analysis, the present and the future are treated more evenhandedly. Typically we discount the future, but the trade-off between today and tomorrow blurs as we move into the future. Tomorrow acquires increasing relative importance as time progresses. It is as if we viewed the future through a curved lens. The relative weight given to two subsequent periods in the future is inversely related to their distance from today. The period-to-period rate of discount is inversely related to the distance into the future. The experimental evidence shows that rate of discount between period $t$ and period $t+1$ decreases with t. Interestingly, studies of human responses to sound summarised in the Weber-Fechner law (Chichilnisky, 1997; Heal, 2000), indicate similar responses to changes in sound intensity. The human ear responds to sound stimuli in an inverse relation to the initial stimulus. Recent research ${ }^{15}$ by Lieberman and Trope (2008) confirms the psychology of transcending the here and now and shows that our mental space traverses temporal, spatial and social distance through the same abstract processing of information. The research shows considerable similarity in the way people mentally traverse these different types of distances, and how we evaluate, predict and plan near and distant situations.

How to explain this experimental evidence, our sensitivity to time, and how to integrate it into an economic criterion of optimality? Several interesting alternatives to the discounted utility analysis have been proposed. So far none had reached the clarity and consistency of the discounted utilitarian criterion used in cost-benefit analysis, nor its analytical tractability. Prominent examples are the 'overtaking criterion' in von Weizacker (1967), Ramsey’s criterion in Ramsey (1928) and Basic Needs in Chichilnisky (1977a-b) and Herrera et al. (1976). However, these criteria are incomplete, 
failing to rank many reasonable paths. For example the ordering induced by the overtaking criterion cannot be represented by a real valued function, making it impractical to use. As a result, they lack the corresponding 'shadow' prices to evaluate costs and benefits in an impartial fashion. These criteria therefore fail on practical grounds. The last section of this article examines these and other criteria that were previously used.

\section{Axioms to build the economics of the future}

In 1996, I proposed simple axioms that capture the concept of sustainability, and derived the welfare criterion which they imply (Chichilnisky, 1996a; 1997). The criterion that emerges also known as 'sustainable preferences' is complete, analytically tractable, and is represented by a real valued and continuous function. In optimisation thus leads to well-defined shadow prices which can be used for a 'sustainable cost-benefit analysis'.

The new axioms have provided internal consistency and ethical clarity. They imply a more symmetric treatment of generations in the sense that neither the 'present' nor the 'future' should be favoured over the other. They neither accept the romantic view which relishes the future without regards for the present, nor the consumerist view which ranks the present above all. The axioms lead to a complete characterisation of sustainable preferences, which are sensitive to the welfare of all generations and offer an equal opportunity to the present and to the future. Trade-offs between present and future consumption are allowed. ${ }^{16}$

The two axioms introduced in Chichilnisky (1996a) require that neither the present nor the future should be 'dictatorial'. This article takes the matter further by solving outstanding issues that were not covered in the original treatment:

1 What is the practical basis for the new axioms, where do they come from? Exactly why and how do individuals change their preferences and start taking into consideration the long term future?

2 How does one identify in practice the 'weight' given to the future?

3 How does one ensure the existence of sustainable solutions?

The three issues were raised in the subsequence literature on the topic (Chichilnisky, 1994; 1996a; 1997; Heal, 2000; Lawuers, 1993; 1997) and are resolved here. We show in Theorem 3 that the new axioms arise from a rational response to a new objective reality, a reaction to new long term physical constraints that we face today and did not exist before, and the weight given to the long run future derives from the losses due to the extinction of a resource in the long run. The two axioms introduced in Chichilnisky (1996a) can be seen as non-dictatorship properties (see also Arrow, 1953; Chichilnisky, 1982). Axiom 1 requires that the present should not dictate the outcome in disregard for the future: it requires sensitivity to the welfare of generations in the distant future. Axiom 2 requires that the welfare criterion should not be dictated by the long-run future, and thus requires sensitivity to the present. ${ }^{17}$ In Chichilnisky (1996a; 1997) we showed that sustainable preferences are different from all other criteria used so far in the analysis of optimal growth and of markets. 
To offer a formal perspective a few definitions are required, for complete definitions see also Chichilnisky (1996a; 2009a). Each generation is represented by an integer g; $\mathrm{g}=1,2, \ldots{ }^{18}$ Each generation $\mathrm{g}$ has a preference that can be represented by a utility function $\mathrm{u}_{\mathrm{g}}$ for consumption of $\mathrm{n}$ goods, some of which could be environmental goods such as water, or soil, so that consumption vectors $\mathrm{x}_{\mathrm{g}}$ are elements of $\mathrm{R}^{\mathrm{n}}$, and $\mathrm{u}_{\mathrm{g}}$ : $\mathrm{R}^{\mathrm{n}} \rightarrow \mathrm{R}^{+}$. The availability of goods in the economy is constrained in a number of ways, for example by a differential equation which represents the growth of the stock of a renewable resource or the accumulation and depreciation of capital. ${ }^{19}$ We chose a utility representation so that each generation's utility function is bounded below by zero and above by $1 .^{20}$ Therefore a utility stream is a sequence of positive real numbers bounded by the number 1 . The space of all utility streams is contained as a bounded set of the space of all infinite bounded sequences of real numbers. The space of feasible utility streams is therefore $\mathrm{F}=\left\{\alpha: \alpha=\left(\alpha_{\mathrm{g}}\right), \mathrm{g}=1,2, \ldots\right.$, where $\left.\alpha_{\mathrm{g}}=\mathrm{u}_{\mathrm{g}}\left(\mathrm{x}_{\mathrm{g}}\right), \mathrm{g}=1 ; 2, \ldots\right\}$, a subset of the space $l_{\infty}$ of all essentially bounded measurable real valued functions on the integers $\mathrm{Z}^{21} \mathrm{~A}$ social welfare function is a real valued function on $l_{\infty}, \mathrm{W}: l_{\infty} \rightarrow \mathrm{R}$ that ranks all possible utility streams in $\mathrm{F}$ is continuous and linear on utility streams, and is sensitive to (increases with) the welfare of every generation.

\section{The present and the future}

\subsection{The present}

Intuitively, the present is represented by all the utility streams which have no future: for any given utility stream, its 'present' is represented by all finite utility steams which are obtained by cutting off the stream after a given number of generations. Formally:

Definition $1 \quad F$ For any utility stream $\alpha$ and any integer $K$ let $\alpha_{K}$ be the ' $K$-cutoff' of the sequence $\alpha$ namely the sequence whose coordinates up to and including the $K$-th are equal to those of $\alpha$, and zero after the $K$-th.

Definition 2 The present consists of all feasible utility streams which have no future: it consists of the cutoffs of all utility streams, as in Definition 1.

\subsection{The future}

By analogy, for any given utility stream $\alpha$ its 'future' is represented by all infinite utility streams which are obtained as the 'tail' resulting from cutting off $\alpha$ after a finite number of generations.

Definition $3 \quad$ The $K$-th tail of $\alpha$ is the sequence whose coordinates up to and including the $K$-th are zero and equal to those of $\alpha$ after the $K$-th generation. 


\subsection{No dictatorship of the present}

Definition $4 \quad A$ welfare function $W: l_{\infty} \rightarrow R$ gives a dictatorial role to the present, and is called a a 'dictatorship of the present', if $W$ is insensitive to the utility levels of all but a finite number of generations, namely $W$ is only sensitive to the 'cutoffs' of utility streams, and disregards the utility levels of all generations from some generation on. Formally, $W$ is a dictatorship of the present if for every $\alpha, \beta$ there exists an $N>0$ such that $W(\alpha)>W(\beta)$ if and only if $W\left(\alpha^{\prime}\right)>W\left(\beta^{\prime}\right)$ for any $\alpha^{\prime}$ and $\beta^{\prime}$ such that $\alpha_{g}=\alpha_{g}^{\prime}$ and $\beta_{g}=\beta^{\prime}{ }_{g}$ for all $g<N$.

The following axiom eliminates dictatorships of the present:

Axiom 1 No dictatorship of the present.

\subsection{No dictatorship of the future}

Definition $5 \quad A$ welfare function $W: l_{\infty} \rightarrow R$ gives a dictatorial role to the future, and is called $a$ 'dictatorship of the future', if $W$ is insensitive to the utility levels of any infinite number of generations, or equivalently it is only sensitive to the utility levels of the 'tails' of utility streams. The welfare criterion $W$ is therefore only sensitive to the utilities of 'tails' of streams, and in this sense the future always dictates the outcome independently of the present. Formally, $W$ is a dictatorship of the present if for every $\alpha, \beta$ there exists an $N>0$ such that $W(\alpha)>W(\beta)$ if and only if $W\left(\alpha^{\prime}\right)>W\left(\beta^{\prime}\right)$ for any $\alpha^{\prime}$ and $\beta^{\prime}$ such that $\alpha_{g}=\alpha_{g}^{\prime}$ and $\beta_{g}=\beta_{g}$ for all $g>N$.

The following axiom eliminates dictatorships of the future:

Axiom 2 No dictatorship of the future.

\subsection{Sustainable preferences}

Definition $6 \quad A$ sustainable preference is a continuous linear function $W: l_{\infty} \rightarrow R$ satisfying Axioms 1 and 2. It is therefore neither a dictatorship of the present nor a dictatorship of the future.

Axioms 1 and 2 apppeared in Chichilnisky (1996a).

\section{Existence and characterisation of sustainable preferences}

Why is it difficult to rank infinite utility streams? Ideally one would like to give an equal weight to every generation. For example, with a finite number $\mathrm{N}$ of generations, each generation can be assigned weight $1 / \mathrm{N}$. But when trying to extend this criterion to 
infinitely many generations one encounters the problem that, in the limit $1 / \mathrm{N} \rightarrow 0$ so that every generation would then be given zero weight. What is done usually to solve this problem is to attach more weight to the utility of near generations, and less weight to future ones. An example is the classic sum of discounted utilities:

$$
W(\alpha)=\sum_{g=1}^{\infty} \mu_{g} \alpha_{g}
$$

where $\forall g, \mu_{g}>0, \sum_{g=1}^{\infty} \mu_{g} \alpha_{g}<\infty$.

Discounted utilities give a bounded welfare level to every utility stream. Two numbers can always be compared, so that the criterion so defined is clearly complete.

However, the sum of discounted utilities is not even-handed: it disregards the long-run future. It was shown in Chichilnisky $(1996 a ; 1997)$ that it is a dictatorship of the present, see Theorem 1 below.

A possible solution to overcome the problem is the criterion defined by the long-run average of a utility stream, a criterion that is used frequently in repeated games. However, this criterion is not even-handed either: it is biased in favour of the future and against the present. It is insensitive to the welfare of any infinite number of generations. It is a dictatorship of the future.

Here matters stood for some time. Asking for the two axioms together, the non dictatorship of the present and the non dictatorship of the future, as I do there, appears almost as if it would lead to an impossibility theorem. Not quite. Let us reason again by analogy with the case of infinite generations. With finitely many generations one may assign weights which decline into the future, and add some extra weight to the last generation. This procedure, when extended naturally to infinitely many generations, is neither dictatorial for the present nor for the future. It is similar to adding to a sum of discounted utilities plus the long-run average of the whole utility stream. Neither part of the sum is acceptable on its own, but together they are. This is in Theorem 2 below (see also Chichilnisky, 1996a; 1997). The fact is somewhat surprising, but what is perhaps more surprising is that the sustainable welfare criteria constructed here, namely the convex sum of a dictatorship of the present and one of the future, exhaust all the continuous utilities that satisfy my two axioms. This means that any continuous sustainable preference must be of the form just indicated. This is Theorem 3 below (see also Chichilnisky, 1996a; 1997).

Although the axioms presented here are reasonable, so far all preferences considered in the literature fail to satisfy them.

\section{Theorem 1}

The following welfare criteria fail our sustainability axioms:

- $\quad$ the sum of discounted utilities, for any fixed discount factor, no matter how small, because it is always a dictatorship of the present, as established in Chichilnisky (1996a)

- Ramsey's criterion, which is seriously incomplete and therefore does not satisfy the definition of a sustainable preference (see Chichilnisky, 1996a; 1997) 
- the overtaking criterion, because it is also incomplete (see Chichilnisky, 1997)

- the 'lim inf' criterion, which is a dictatorship of the future (Chichilnisky, 1997)

- long-run averages, because it is a dictatorship of the future and also incomplete

- Rawlsian rules, which are insensitive, since they rank the same two streams as long as the infimum achieves the same welfare (see Chichilnisky, 1997)

- Basic Needs because they are insensitive as defined here, since they rank as equal two paths that have the same infimum - even though one may assign a much higher utility to many (even to infinitely many) generations

- the Green Golden Rule g, a stationary path that achieves the maximum utility level which is sustainable forever.

For definitions of the welfare criteria referred to above, see the Appendix. A proof of this theorem is in Chichilnisky (1996a; 1997).

\subsection{Existence of sustainable preferences}

Theorem 2

There exists a sustainable preference $W: l_{\infty} \rightarrow R$, i.e., a preference which is continuous and linear on utility streams and does not assign a dictatorial role to either the present or the future.

$$
W(\alpha)=\sum_{g=1}^{\infty} \mu_{g} \alpha_{g}+\Phi(\alpha)
$$

where $\forall g, \mu_{g}>0, \sum_{g=1}^{\infty} \mu_{g} \alpha_{g}<\infty$ and where $\Phi(\alpha)$ is the function $\Phi(\alpha)=\lim _{g \rightarrow \infty} \alpha_{g}$ when this limit exists, and extended to all $l_{\infty}$ otherwise using Hahn Banach's theorem.

For a proof see Chichilnisky (1996a; 1997).

\subsection{Complete characterisation of sustainable preferences}

The existence theorem presented above has been extended to provide a complete characterisation of sustainable preferences in Chichilnisky (1996a; 1997):

Theorem 3

Let $W: l_{\infty} \rightarrow R$ be a continuous linear sustainable preference. Then $W$ is of the form:

$$
W(\alpha)=(1-\lambda) \sum_{g=1}^{\infty} \mu_{g} \alpha_{g}+\lambda \Phi(\alpha)
$$

where $\forall g, \mu_{g}>0, \sum_{g=1}^{\infty} \mu_{g} \alpha_{g}<\infty$ and where $\Phi(\alpha)$ is a finitely additive measure on $l_{\infty}$. 


\section{How we change preferences}

This section explains how we change preferences, and provides a practical criterion to explain why we should accept the Axioms 1 and 2 defined above. Consider sustainable preferences that take into consideration environmental assets in the long term future. The theorem below proves that maximising a sustainable preference is mathematically equivalent to maximising a standard preference with a a new additional constraint in the long run, a survival constraint that did not exist before. An immediate corollary of the theorem below is that if we are aware of a new physical constraint in the long run, and we consider these new constraints in making decisions, then we must accept the new axioms and the attendant decision criteria that they define.

The theorem presented below was established in Chichilnisky (2009a) and resolves also an outstanding issue that was pointed out about sustainable preferences: it identifies in practical terms the 'weight' that sustainable preferences assign to the long term future, appearing in the characterisation Theorem 2 above and in Chichilnisky (1996a; 1997). This parameter can be identified with the marginal value of an environmental asset that could disappear in the long run, computed at the point of its extinction. We need a few definitions to link this results with those presented above.

Consider a standard optimisation problem where one maximises a continuous linear increasing function on the space of all sequences of utilities:

$$
W(\alpha)=\sum_{g=1}^{\infty} \mu_{g} \alpha_{g}
$$

where $\forall g, \mu_{g}>0, \sum_{g=1}^{\infty} \mu_{g} \alpha_{g}<\infty$.

This $\mathrm{W}$ is a called standard discounted utility preference over infinite streams.

The following establishes the equivalence between two optimisation problems:

1 optimising a sustainable preference

2 optimising a standard preference with an additional constraint in the long run, namely at infinity.

The result suggests how sustainable preferences emerge from standard preferences: upon the consideration of new constraints at infinity such as, for example, new survival constraints on a renewable resource (such as an animal species) - a constraint that was not considered or did not exist before (Chichilnisky, 2009a). The value of the 'weight' that sustainable preferences assign to the long run future in Theorem 2 is the shadow price of the new added constraint at infinity. For example, when the constraint represents a requirement to avoid extinction of the species, then the parameter that appears in the second term of the sustainable preference, the term that represents the value of the long run future, is identified with the marginal utility of this renewable resource at the point near extinction. We now assume that all feasible utility streams have a well defined limit at infinity. Then:

\section{Theorem 4}

The following two optimisation problems are equivalent: 
Problem 1 Optimise a standard discounted utility $W$ with an additional constraint at infinity namely:

$$
\operatorname{Max}_{\alpha \in \Omega \subset l_{\infty}}\left(W(\alpha)=\sum_{g=1}^{\infty} \mu_{g} \alpha_{g}\right)
$$

where $W(\alpha)=\sum_{g=1}^{\infty} \mu_{g} \alpha_{g}, \mu_{g} \in l_{1}: \forall g, \mu_{g}>0$ and $\sum_{g=1}^{\infty} \mu_{g} \alpha_{g}<\infty$, and the additional constraint at infinity:

$$
\lim _{g \rightarrow \infty} \alpha_{g} \geq K
$$

Problem 2 Optimise a sustainable preference as characterised in Theorem 3, with no constraint at infinity, namely:

$$
\operatorname{Mox}_{\alpha \in \Omega \subset l_{\infty}} W^{*}(\alpha)=\operatorname{Mox}_{\alpha \in \Omega \subset l_{\infty}}\left\{\sum_{g=1}^{\infty} \mu_{g} \alpha_{g}+\lambda \Phi(\alpha)\right\} \text {. }
$$

\section{Conclusions}

It is indisputable that we face physical limits that did not exist or were not as evident before. In particular we are now aware of the possibility of the extinction of our species in the long run. This article says that this awareness leads us to behave according to the new axioms (Chichilnisky, 1996a; 1997) and the decision criterion that they imply. The new decision criteria have practical implications across economics: for cost benefit analysis, for choice under uncertainty with catastrophic events, for optimal extraction of renewable resources, the economics of markets. The new types of sustainable preferences have been tested experimentally and used to identify the limits of non - parametric econometrics (Chichilnisky, 2009c). They could be the foundation for a new type of economics, the economics of the future, which could help us reach new sustainable goals.

We all have somewhat different preferences. Yet if there is something on which most people would seem to agree, that is the desirability of the survival of the species. This is a goal for the economics of the future. Economics has caused the major environmental risks of our times, and the economics of the future must be more aligned with our goals as a species.

\section{Acknowledgements}

The author is UNESCO Professor of Mathematics and Economics and Director, Program on Information and Resources, Columbia University. Research support from NSF grant No. 92-16028 to the Program on Information and Resources at Columbia University, the Stanford Institute for Theoretical Economics (SITE), and from the Institute for International Studies at Stanford University is gratefully acknowledged, as are the comments of Y. Baryshnikov, P. Ehrlich, P. Eisenberger, C. Figuieres, S.C. Kolm, D. Kennedy, D. Kreps, L. Lauwers, C. Perrings, D. Starrett, L. van Liedekierke, 
P. Milgrom, J. Roberts, R. Wilson, and H.M. Wu. Special thanks are due to Kenneth Arrow, Peter Hammond, Geoffrey Heal, Mark Machina, Robert Solow, Richard Howarth. The initial research for this article was prepared for an invited presentation at a seminar on Reconsideration of Values at the Stanford Institute for Theoretical Economics, organised by K.J. Arrow in July 1993. It was also an invited presentation at the Intergovernmental Panel on Climate Change (IPCC) Seminar in Montreux, Switzerland, March 1994, at a Seminar on Inconmensurability of Values at Chateaux du Barry, Normandy, April 1994, and at the Graduate School of Business of Stanford University in May 1994, in 2007 at the School of Economics, Oslo University in Norway, Department of Mathematical Statistics Columbia University, 2007, in 2008 at GREQAM Universite de Marseille France and at the Universite de Montpellier, France.

\section{References}

Arrow, K.J. (1953) Social Choice and Individual Values, Cowles Foundation Monographs, New York: Wiley.

Arrow, K.J. (1964) Essays in the Theory of Risk Bearing, New York: Wiley.

Beltratti, A., Chichilnisky, G. and Heal, G.M. (1995) 'The green golden rule: valuing the long run', Economics Letters, Vol. 49, No. 2, pp.175-179.

Brundtland, G.H. (1987) 'The U.N. World Commission on environment and development', Our Common Future, Oxford: Oxford University Press.

Chanel, O. and Chichilnisky, G. (2008) 'The influence of fear in decisions', Working Paper CNRS-GREQAM-IDEP Universite de Marseille.

Chichilnisky, G. (1977a) 'Development patterns and the international order', Journal of International Affairs, Vol. 31, No. 2, pp.275-304.

Chichilnisky, G. (1977b) 'Economic development and efficiency criteria in the satisfaction of basic needs', Applied Mathematical Modeling, Vol. 1, No. 6, pp.290-297.

Chichilnisky, G. (1977c) 'Nonlinear functional analysis and optimal economic growth', Journal of Mathematical Analysis and Applications, 15 November, Vol. 61, No. 2, pp.504-520.

Chichilnisky, G. (1982) 'Social aggregation rules and continuity', Quarterly Journal of Economics, Vol. 97, No. 2, pp.337-352.

Chichilnisky, G. (1994) 'The environment and the long run: a comparison of different criteria', with A. Beltratti and G.M. Heal, Richerche Economiche, Vol. 48, pp.319-340.

Chichilnisky, G. (1995a) 'Sustainable growth and the green golden rule' (presented with A. Beltratti and G.M. Heal at the Conference on Sustainable Growth, Paris, May 1993), in I. Goldin and A. Winters (Eds.) Conference Economic Approaches to Sustainable Development, OECD, Paris, pp.147-165.

Chichilnisky, G. (1995b) 'The green golden rule', with G. Heal and A. Beltratti, Economic Letters, August, Vol. 49, No. 2, pp.175-180.

Chichilnisky, G. (1996a) 'An axiomatic approach to sustainable development', Social Choice and Welfare, Vol. 13, No. 2, pp.231-257.

Chichilnisky, G. (1996b) 'Social diversity, arbitrage and gains from trade: a unified perspective on resource allocation', American Economic Review, Vol. 84, No. 2, pp.427-434.

Chichilnisky, G. (1997) 'What is sustainable development', Land Economics, Vol. 73, No. 4, pp.467-491.

Chichilnisky, G. (1998a) 'Economics returns from the biosphere', Nature, 12 February, Vol. 391, pp.629-630. 
Chichilnisky, G. (1998b) 'Sustainable development and north-south trade', in L.D. Guruswamy and J.A. McNeely (Eds.) Protection of Global Biodiversity: Converging Strategies, Durham/London: Duke University Press, pp.101-117.

Chichilnisky, G. (1998c) 'Sustainable use of renewable resources', with A. Beltratti and G.M. Heal, Chap. 2.1 in G. Chichilnisky, G.M. Heal and A. Vercelli (Eds.) Sustainablity: Dynamics and Uncertainty, The Netherlands, Kluwer Academic Publishers, pp.49-76.

Chichilnisky, G. (1998d) 'Uncertain future preferences and conservation', with A. Beltratti and G.M. Heal, Chap. 3.4 in G. Chichilnisky, G.M. Heal and A. Vercelli (Eds.) Sustainability: Dynamics and Uncertainty, The Netherlands: Kluwer Academic Publishers, pp.257-276.

Chichilnisky, G. (2000a) 'An axiomatic approach to choice under uncertainty with catastrophic risks', Resource \& Energy Economics, July, Vol. 22, No. 3, pp.221-231.

Chichilnisky, G. (Ed.) (2000b) Mathematical Economics, Library of Critical Essays in Economics, UK: Edward Elgar, Vols. 1-3.

Chichilnisky, G. (2002) 'Catastrophic risk', in A.H. El-Shaarawi and W.W. Piegorsch (Eds.) Encyclopedia of Environmetrics, Chichester, UK: John Wiley \& Sons, Ltd., Vol. 1, pp.274-279.

Chichilnisky, G. (2006) 'Catastrophic risks: the need for new tools, financial instruments and institutions', Symposium on the Privatization of Risk, Social Science Research Council, New York, June.

Chichilnisky, G. (2009a) 'Avoiding extinction: equal treatment for the present and the future', Working Paper, University of Montpellier, Fall.

Chichilnisky, G. (2009b) Beyond the Global Divide: From Basic Needs to the Knowledge Revolution, Manuscript, Columbia University, New York.

Chichilnisky, G. (2009c) 'Non parametric estimation in Hilbert spaces: the limits of econometrics', Econometric Theory, Spring.

Chichilnisky, G. and Baryshnikov, Y. (1999) 'Intergenerational choice: a paradox and a solution', in G. Chichilnisky (Ed.) Topology and Markets, American Mathematical Society and Field Institute for Mathematical Sciences, Vol. 22, pp.99-110.

Chichilnisky, G., Heal, G. and Vercelli, S. (1998) Sustainability, Dynamics and Uncertainty, Kluwer Academic Publishers.

Chichilnisky, G. and Kalman, P.J. (1980) 'Application of functional analysis to models of efficient allocation of economic resources', Journal of Optimization Theory and Applications, Vol. 30, pp.19-32.

Chichilnisky, G. and Sheeran, K. (2009) Saving Kyoto, New Holland, UK, Fall, in press.

Cline, W.R. (1992) The Economics of Global Warming, Washington, DC: Institute for International Economics.

Cropper, M.L., Aydede, S.K. and Portney, P. (1994) 'Preferences for lifesaving programs: how the public discounts time and age', Journal of Risk and Uncertainty, Vol. 8, pp.243-265.

Dasgupta, P. and Heal, G. (1979) Economic Theory and Exhaustible Resources, Cambridge: Cambridge University Press.

Debreu, G. (1953) 'Competitive equilibrium and pareto optimum', Proceedings of the National Academy of Sciences.

Dutta, P. (1991) 'What do discounted optima converge to?', Journal of Economic Theory, Vol. 55, pp.64-94.

Epstein, L. (1986) 'Intergenerational consumption rules: an axiomatization of utilitarianism and egalitarianism', Journal of Economic Theory, Vol. 38, pp.280-297.

Hammond, P.J. (1993) 'Is there anything new in the concept of sustainable development?', Presented at the Conference the Environment after Rio, Courmayeur, Italy, 10-12 February.

Heal, G. (2000) Valuing the Future: Economic Theory and Sustainability, Columbia University Press. 
Herrera, A., Chichilnisky, G., et al. (1976) Catastrophe or New Society: A Latin American World Model (The Bariloche Model), International Development Research Center, Ottawa, Canada.

Hoerschele, W. (2008) 'Research agenda for a green economics of abundance', Int. J. Green Economics, Vol. 2, No. 1, pp.29-45.

Kennet, M. (2006) 'Towards a philosophy of Green Economics. Asking some questions about paradoxes in the green position', Proceedings of the Philosophy of Green Economics Conference, Friends Meeting House Lancaster, Lancaster, 18 November, LA1 1TJ, Green Economics Institute, Lancaster, UK, ISBN: 0-9554646-2-5.

Kennet, M. (2008) 'Green Economics. An introduction to progressive economics', Harvard School Economics Review, Vol. 2, No. 1, p.19.

Kennet, M. and Heinemann, V. (2006) 'Green Economics setting the scene', Int. J. Green Economics, Geneva: Inderscience Publishers, Vol. 1, Nos. 1-2, pp.68-103.

Koopmans, T.C. (1960) 'Stationary ordinal utility and impatience', Econometrica, Vol. 28, p.287.

Krautkramer, J. (1985) 'Optimal growth, resource amenities and the preservation of natural environments', Review of Economic Studies, Vol. 52, pp.153-170.

Lauwers, L. (1993) 'Infinite Chichilnisky rules', Economics Letters, Discussion paper, Katholik Universitaet, Leuven, March-April, Vol. 42, No. 4, pp.349-352.

Lauwers, L. (1997) 'A note on weak - Chichilnisky rules', Social Choice and Welfare, Vol. 14, No. 2, pp.357-359.

Liberman, N. and Trope, Y. (2008) 'The psychology of transcending the here and now', Science, 21 November, Vol. 322, pp.1201-1205.

Lowenstein, G. and Elster, J. (Eds.) (1992) Choice Over Time, New York: Russell Sage Foundation.

Lowenstein, G. and Thaler, R. (1989) 'Intertemporal choice', Journal of Economic Perspectives, Vol. 3, No. 4, pp.181-193.

Nature (1998) 'When self interest is key to a better environment', Nature - Briefing in Ecology and Economics, Vol. 395, 1 October, pp.428-429.

Pigou, A.C. (1932) The Economics of Welfare, London: Macmillan.

Ramsey, F. (1928) ‘A mathematical theory of saving', Economic Journal, Vol. 38, pp.543-559.

Rawls, J. (1971) A Theory of Justice, Cambridge, MA: Bellknap Press.

Schipper, J., et al. (2008) 'The status of the worlds land and marine mammals: diversity threat and knowledge', Science, 10 October, pp.225-229.

Solow, R. (1992) 'An almost practical step toward sustainability', Lecture on the Occasion of the Fortieth Anniversary of Resources for the Future, Washington, DC, October.

Solow, R.M. (1974) 'Intergenerational equity and exhaustible resources', Review of Economic Studies, Symposium, Vol. 2945, No. 32.

United Nations (UN) (2000) UN 2000 Millenium Report, New York.

Von Weizacker, C.C. (1967) 'Lemmas for a theory of approximate optimal growth', Review of Economic Studies, Vol. 34, January, pp.143-151. 


\section{Notes}

1 Whereas we face a range of future catastrophic risks, extinction is chosen here as an example that is of general concern, since there seems to be uniform agreement about the goal of avoiding it.

2 Catastrophic risks could cause extinction. For data on extinction rates, see Schipper et al. (2008) and UN (2000).

3 Global warming risks emerge mostly from the use of fossil energy in industrial production; biodiversity destruction in land and seas and the depletion of clean water sources originate in our use of natural resources, such as watersheds, forests, the oceans, and the animal species that populate them, for production and trade through international markets. Economics, and particularly market economics, are heavily implicated in all these matters.

4 ILO is the International Labor Organization of the UN.

5 The concept of development based on the satisfaction of basic needs was introduced in the mid 1970s in the Bariloche Model and several other publications (Chichilnisky 1977a-b). At the Earth Summit of Rio de Janeiro 1992, the concept of basic needs was voted by 150 nations as the main concept of development and the Brundlands Report in 1987 defined sustainable development explicitly on the basis of basic needs, as "a form of development that satisfies the needs of the present without preventing the future from satisfying its own needs".

6 See Chichilnisky (2009b).

7 Most of the overuse of natural resources occurred since WWII when the Bretton Woods institutions were created to encourage international trade (Chichilnisky, 2009b).

8 Robert Solow pointed out that discussion of sustainability has been mainly an occasion for the expression of emotions and attitudes, with very little formal analysis of sustainability or of sustainable paths for a modern industrial economy. One purpose of Chichilnisky (1996a; 1997) was to attempt to resolve this problem.

9 Standard cost-benefit analysis discounts and undervalues the future. It is therefore biased against policies designed to provide benefits in the very long run. An example is the evaluation of projects for the disposal of waste from a nuclear power plant. Another is policies designed for the prevention of global warming. The benefits of both may be at least 50 to 100 years into the future. The costs, however, are here today. In these cases, the inherent asymmetry between the treatment of present and future makes it hard to justify investment decisions that large numbers of individuals and organisations clearly feel are well merited.

10 Neoclassical theory of choice and preference theory was developed in the first part of the 20th century based in axioms from which present discounted value and expected utility analysis were derived. They were created by Tjallings Koopmans for the case of choice over time and by John von Neumann Von Neumann for the case of choice under uncertainty and grew to achieve the status of common knowledge.

11 According to the UN (2000).

12 Of the 5487 known species of mammals - our relatives - 25\% have become extinct sending a somber message to the rest (see Schipper et al., 2008).

13 Yet, as pointed out above, little progress has been achieved since then. The use of biodiversity and fossil fuels has increased rapidly and water is now the most scarce resource in the world.

14 For example, in a recent presentation I gave at a Seminar in Cargese, France, Spring of 2008 Charles Perrings argued that the criterion of sustainable preferences that arises from my two axioms is less applicable if we do not know the exact value of the parameter that appears in front of the long run future utility. A similar point was made by a Columbia University colleague, Peter Eisenberger.

15 See Liberman and Trope (2008).

16 The existence and characterisation of sustainable preferences appears in Chichilnisky (1996a), Theorems 1, 2 and 3 and sustainable preferences were shown in Chichilnisky (1996a) to be a natural extension of the "equal treatment criterion" for finitely many generations, in the sense 
that the optimal solutions for such preferences approach the "turnpike" of an equal-weight finite horizon optimisation problem as the horizon increases (Chichinisky, 1996a). Theorem 3 of Chichilnisky (1996a) showed that sustainable preferences match the experimental evidence in these cases, in the sense that they imply a rate of discount that decreases and approaches zero as time goes to infinity, and Theorem 4 investigated the relationship between the optimal paths according to sustainable preferences and discounted utilitarianism in an extension of the classical Hotelling problem of the optimal depletion of an exhaustible resource. Theorem 5 in Chichilnisky (1996a) showed that sustainable optima can be quite different from discounted optima, no matter how small is the discount factor. Subsequent examples show the implications for shadow prices.

17 An alternative name suggested by Robert Solow in personal communication is "inter-temporally equitable preferences".

18 An infinitely lived world obviates the need to make decisions contingent on an unknown terminal date. Generations could overlap or not. Indeed agents could be infinitely long-lived and evaluate development paths for their own futures. For ease of comparison, I adopt a formulation which is as close as possible to the standard neoclassical model.

19 Ignore for the moment population growth, although this issue can be incorporated with little change in the results, at the cost of more notation.

20 This choice is not restrictive: it was shown by Arrow (1964) that when ranking infinite streams of utilities as done here one should work with bounded utility representations since doing otherwise could lead to paradoxes. The need to work with bounded utility representation in models with infinitely many parameters was pointed out by Arrow (1964), who required boundedness to solve the problem that originally gave rise to Daniel Bernouillis famous paper on the St. Petersburg Paradox Utility Boundedness Theorem (Arrow, 1964, p.27).

$21 l_{\infty}(\mathrm{Z})$ denotes the space of all essentially bounded sequences of real numbers endowed with a standard Banach space structure, defined by the sup norm, where the norm of a sequence is defined as the (ess.) supremum of its absolute values, a space of sequences that was first used in economics by Debreu (1953). 


\section{Appendix}

\section{(a) Continuity and linearity of sustainable preferences}

In practical terms the continuity of $\mathrm{W}$ is the requirement that there should exist a sufficient statistic for inferring the welfare criterion from actual data. This is an expression of the condition that it should be possible to approximate the welfare criterion $\mathrm{W}$ as closely as desired by sampling over large enough finite samples of utility streams. Continuity of a sustainable criterion function $\mathrm{W}$ is not needed in Theorem 1; it is used solely for the characterisation in Theorem 2. Continuity is defined here in terms of the standard topology of sup norm first used in economics by Debreu (1953). Linearity is a standard requirement that is satisfied, for example, by discounted utilities.

\section{(b) Previous welfare criteria: definitions}

A function $W: l_{\infty} \rightarrow R$ is called a discounted sum of utilities if it is of the form:

$W(\alpha)=\sum_{g=1}^{\infty} \mu_{g}, \alpha_{g}$ where $\forall g, \alpha_{g} \geq 0$ and $\sum \mu_{g}<\infty, \mu_{g}$ is called a 'discount factor'.

Ramsey's welfare criterion ranks a utility stream $\alpha=\left(\alpha_{g}\right) g=1,2, \ldots$ above another $\beta=\left(\beta_{g}\right) g=1,2, \ldots$ if the utility stream $\alpha$ is 'closer' to the bliss path, namely to the sequence $t=(1,1, \ldots, 1 \ldots)$, than is the sequence $\beta$. Formally: $\sum_{g=1}^{\infty} 1-\alpha_{g}<\sum_{g=1}^{\infty} 1-\beta_{g}$.

A Rawlsian rule ranks two utility streams according to which has a higher infimum value of utility for all generations. This is a natural extension of the criterion proposed initially by Rawls. Formally: a utility stream a is preferred to another if $\inf \left(\alpha_{g}\right)>\inf \left(\alpha_{g}\right)$. The criterion of satisfaction of basic needs introduced in Chichilnisky $(1977 \mathrm{~b}-\mathrm{c})$ ranks a utility stream $\alpha$ over another $\beta$ if the time required to meet basic needs is shorter in $\alpha$ than in $\beta$. Formally: $T(\alpha) \leqq T(\beta)$ where $T(\alpha)=\min \left\{t: \alpha_{t}>b\right\}$, for a given $b$ which represents basic needs. The overtaking criterion ranks a utility stream $\alpha$ over another $\beta$ if $\alpha$ eventually leads to a permanently higher level of aggregate utility than does $\beta$. Formally: $\alpha$ is preferred to $\beta$ if $\exists n$ such that:

$$
\forall M>N, \sum_{g-1}^{M}\left(\alpha_{g}\right)>\sum_{g-1}^{M}\left(\beta_{g}\right) .
$$

The long-run average criterion can be defined in our context as follows: a utility stream $\alpha$ is preferred to another $\beta$ if in average terms, the long-run aggregate utility achieved by $\alpha$ is larger than achieved by $\beta$. 